\title{
Research on the Construction of Visual Aesthetic Factors in Graphic Design
}

\author{
Hu Maosheng \\ Chongqing Business Vocational College, Chongqing, China \\ hmshumaosheng@163.com
}

Keywords: Visual Aesthetic Factors, Graphic Design, Construction Method

\begin{abstract}
With the rapid social and economic development, people's aesthetic needs are also getting higher and higher, especially in some brands of brand awareness in graphic design through the construction of visual aesthetic elements, to meet people's aesthetic needs, but also to achieve the product Propaganda role. Therefore, in the process of graphic design, pay attention to its impact on the visual effect, is of great significance to graphic design. This paper mainly discusses the construction of visual aesthetic elements in graphic design.
\end{abstract}

\section{Introduction}

Graphic design is playing a more and more significant role in commercial advertising, with a wide variety of graphic designs, such as posters and advertisements, everywhere. Graphic design can not only decorate people's living environment, but also broaden people's horizons. The constantly updated graphic design is affecting people's visual aesthetic. In the graphic design creation, designers should consider whether the design style and shape of the text can attract people's attention, and also consider whether the expression of the text can be accepted by the people. At the same time, it is also necessary to consider whether the collocation of the figure and the text can be met Theme of the request. The article discusses the visual aesthetic elements in graphic design. By analyzing the structural elements and aesthetic features in graphic design, we find out how to construct visual aesthetic elements.

\section{Graphic Design Elements of the Aesthetic Characteristics}

Elements involved in graphic design include the order of the United States, visual impact, artistic functionality, etc., designers only rational use of the various elements in order to create a good print. First, the order of the United States. Graphic design of the scientific elements of the design of the multi-performance in the order of the United States, the designer of the design object visualization, specific treatment. The beauty of order in graphic design mainly manifests itself in the constituent elements of the design works. Grasping the order beauty can make people feel visually comfortable and balanced when they contact with the design works, and can also help people to improve the aesthetic ability to meet people Visual aesthetic needs. Second, visual impact. Designers in the graphic design creation, should be the proper use of color, text, graphics and other elements, fully demonstrate their design features, so that people can enjoy the United States. Designers want to make their own graphic design works with a strong visual impact, it is necessary to make visual aesthetic elements in a very short period of time to attract people's attention, so that people quickly perceived the theme of design. Because of different people's social backgrounds, psychological characteristics are different, their aesthetic is not the same. Therefore, designers should carry out research on specific groups of people in the process of graphic design creation, thus bringing strong visual impact to people. Third, artistic functionality. With the continuous development of the times, if designers want to make their graphic design works, they need to consider the degree of customer acceptance and gain the trust of customers. The most important thing is to stand the test of the 
market. Design works to beautify the product at the same time, but also to promote consumer spending, so as to achieve the purpose of marketing. Market trends are volatile, designers only continue to innovate, in order to adapt their works to market changes.

Visual aesthetic elements are an integral part of graphic design and have many important implications for graphic design. First of all, visual aesthetic elements can improve the economic utility of graphic design work. Graphic design works mainly used in the field of commercial packaging, consumers in the process of purchasing goods is the first contact with the packaging of goods. Therefore, through the rational design and application of graphics, texts and colors, consumers will be able to attract the attention of consumers in the shortest time so that consumers can pay attention to the products and purchase and use the products so as to promote the economic benefits of the merchants. Therefore, the visual aesthetic elements in the application of graphic design work has a certain economic effect, many merchants in the process of commodity production, attach great importance to the visual aesthetic elements in the design of the product, so that the goods more competitive. Second, visual aesthetic elements can show the beauty of the order of the graphic design work. Visual aesthetic dollars in the use of graphic design is a certain law, not a combination of color, graphics, text random accumulation, giving a sense of orderly beauty. This kind of order beauty not only enhances the aesthetic value of the graphic design work, but also better conveys the information to be expressed in the graphic design work. Therefore, pay attention to the graphic design of visual aesthetic elements of the order of construction, to better ensure the flat works of information is complete and accurate. Third, the original assumption of visual aesthetics can reflect the creativeness of graphic design works. Visual aesthetic elements not only reflect the graphic design to convey the content, but also reflects the innovative graphic design. Rapid social and economic development, the market competition between goods more and more fierce, if you want to dominate the competition in the commodity, the quality of the goods themselves to ensure the clearance, but also pay attention to the unique packaging design. Therefore, during the process of graphic design, we must innovate the construction of visual aesthetics elements, make the designed flat patterns unique, attract the attention of consumers and firmly grasp the aesthetic habits of consumers. At the same time, Satisfy the aesthetic needs of consumers, based on the realization of the marketing of goods.

\section{Graphic Design Aesthetic Elements of the Building}

In graphic design, text is a key element that can serve as a finishing touch. Hieroglyphs are the initial form of writing, but there are more hieroglyphs and strokes, the structure is complicated and the writing is inconvenient. Later, people simplified the hieroglyphs and the present text appeared. Text often appears in graphic design. In graphic design, designers need to deal with the text, rich text features, improve text expressiveness. A key element of the image is the design of fonts, the purpose of which is to accurately convey a variety of information. Therefore, in the design of fonts, designers need to coordinate the relationship between words and words, scientifically match the lines, arrange the structure, emphasize the rhythm and rhythm. In addition, the text can also convey the cultural connotation, enhance the sense of art, improve visual effects. At present, the graphic design of the main text design slogan, title and body. In the design of print ads, designers should decompose the font, in accordance with the composition of the text needs to be reorganized and text layout, from the point, line, surface and other levels of design, to create a variety of rich forms and improve the picture effect. Or through the transformation of the image of the image, shape the sound to enhance the visual impact and appeal, improve font expression, clear font design theme, to attract the attention of the audience.

The colors of the graphics are not single but varied. Designers want to show the best results, first of all need to be different with the background color. For example, in the design of tea packaging, designers can use a simple teapot sketch as the main figure to reflect the ancient flavor, the product surface can choose light brown, light yellow, light gray and other colors. If the color replaced by bright green, red, etc., can not reflect its content. Second, designers should make the color and market positioning consistent. Different consumers have different preferences for color and 
different color understanding. Therefore, designers in the design of product colors, should pay attention to consider the characteristics of different target groups. For example, children's ability to identify color has not yet fully developed, color recognition is not strong, prefer bright colors. Therefore, when designing children's product packaging, designers can use more lively and cheerful colors, such as green, blue and red, to attract children's attention. Adults with complex feelings, rich life experiences and mature psychology, they prefer coordinated, rich, subtle colors. Therefore, the designer can design products according to the characteristics of the target people to expand sales of products. Finally, designers need to increase their color-inducing ability to meet consumer demand for product appearance. Graphic designers have good ability to use color, so when designing colors, you can use a variety of colors to highlight the content of the works so that consumers can trigger their own purchase desire when they see the products.

The level of graphics and the traction of the visual line in the graphic design, it is important to pay attention. Among them, the level of graphics, graphic design can make people feel more vivid, highlighting the contents of the plane to be expressed, so clear, clear primary and secondary, so that consumers can see in the shortest time what this product, And what is the advantage of this product compared to other products. Therefore, in the composition of graphic design, we must pay attention to the graphic level, the expression of the content of careful analysis, put forward the theme of the work, to avoid the cart before the horse, or the expression of the content is not accurate, not clear. In the meantime, during the process of plane composition, some graphic element effects are properly inserted so that the theme of the work can be better expressed. The drawing effect of the visual line of graphic design refers to the use of people's different perceptions of different colors to achieve the purpose of enjoying the public. In graphic design, you can compose artwork based on the subjective perception of people of different colors. For example, during the Chinese New Year, red represents auspiciousness and festivity, so red is the most commonly used color for graphic design of annual goods. Also, many cookies, breads and other packaging design will use the orange color, because most people see the orange will think of sweet fruits, resulting in buying desire.

In real life, through the clever design of the text color and shape, so as to achieve the different aesthetic effects of the phenomenon is very common. With the development of society, the text gradually increases the role of visual aesthetics on the basis of basic reading. Therefore, during the process of graphic design, it should be properly landscaped on the basis of not affecting the identification of text information, so that the text has more aesthetic effect. Of course, in the process of word processing, not only to meet consumer aesthetic habits, the most important thing is to fit the theme of the product, to avoid any further consideration.

In graphic design, the use of color is a key consideration. In today's era, different fields and different audiences have different requirements for color. In order to make the graphic design works better visual effects, on the basis of expressing the idea of the works, but also to meet a few requirements. First of all, the use of color to meet the needs of goods. Graphic design is mainly used in the use of trademarks of goods in order to enhance the market competitiveness of goods. Therefore, the use of graphic design color to achieve the service of goods to promote the marketing of goods. Second, the use of color in the process, we should focus on coordination with the graphics, graphics to play the role of color, but also to use colors to represent graphics. Finally, is the unity of color and commodity market positioning. Different consumer groups also have different preferences for color, so in graphic design, we must fully consider the audience of products and market positioning so that the color and market positioning of goods can be consistent. For example, children usually like bright colors, and the design of toys, children's snacks and the like should focus on the bright colors and bright colors. Adults, on the other hand, prefer to be relatively reserved and rich in content.

\section{Conclusion}

Most of the graphic design work is to serve the goods, so, in the design of graphic design visual aesthetics, the use of graphics, text and color, based on the completion of the theme of the product, but also to meet the consumer Aesthetic needs. In this way, the design of the product brand can 
really attract people's attention, for people to bring a visual impact, so as to realize the product of publicity services.

\section{References}

[1] Ji winter. Visual aesthetic elements in graphic design [J]. Art and Technology. 2014 (06)

[2] Guo Zhenshan. The traditional window decoration art in contemporary graphic design [J]. Fine Arts. 2017 (08)

[3] Zhou Xing, Chen Chun. New Year's plank in graphic design [J]. Packaging Engineering. 2017 (18)

[4] Thousands, Huang Lusha. Plane Unevenness - A Study of Innovative Products Driven by Plane Thinking [J]. Journal of Art of Arts. 2017 (03)

[5] Gao Wei. Photography technology in the graphic design of the application of [J]. Private Science and Technology. 2017 (09)

[6] John L. Walters, Pomona, Roque Buymacher [J]. World Art. 2017 (03)

[7] Yu Nan. Research on the Art Rules of Composition in Graphic Design [J]. Heilongjiang Science. 2017 (16) 